\title{
Fingerprint for Personal Identification: A Developed System for Students Attendance Information Management
}

\author{
Blessed Olalekan Oyebola, Kayode Oluwabukola Olabisi, Oyerinde Solomon Adewale
}

Department of Computer Engineering Technology, Gateway (ICT) Polytechnic Saapade, Remo North, Nigeria

\section{Email address:}

blessedolalekan@gmail.com (B. O. Oyebola)

\section{To cite this article:}

Blessed Olalekan Oyebola, Kayode Oluwabukola Olabisi, Oyerinde Solomon Adewale. Fingerprint for Personal Identification: A Developed System for Students Attendance Information Management. American Journal of Embedded Systems and Applications.

Vol. 6, No. 1, 2018, pp. 1-10. doi: 10.11648/j.ajesa.20180601.11

Received: December 19, 2017; Accepted: December 29, 2017; Published: January 17, 2018

\begin{abstract}
Today many educational institutions use the manual system of taking attendance in which student writes their names and matric numbers on a sheet of paper or in an attendance sheet. To eradicate the problem associated with the manual attendance system such as student not coming to class, writing of names for students who are not present, an automated approach is implemented through biometric technology embedded with a window application which is fully explained in this work. This paper presents design and construction of student attendance management system. The developed system comprises of a timekeeping system that will register every student in a database. The database itself will be managed by the department, so that reports, either individual or collective, can be issued whenever they are needed on both physical and electronic format. Also, these reports would be used to create statistics and further help the growth of the academic process.
\end{abstract}

Keywords: Attendance, Radio, Fingerprint, Student

\section{Introduction}

Fingerprints are considered to be the best and fastest method for biometric identification. They are secured to use, unique for every person and do not change in one's lifetime. Besides these, implementation of fingerprint recognition system is cheap, easy, accurate and satisfactory [1]. Fingerprint recognition has been widely used in both forensic and civilian applications. Compared with other biometrics features, fingerprint-based biometrics is the most proven technique and has the largest market shares [2]. Not only it is faster than other techniques but also the energy consumption by such systems is less. When human fingerprint experts determine if two fingerprints are from the same finger, the matching degree between two minutiae pattern is one of the most important factors. Thanks to the similarity to the way of human fingerprint experts and compactness of templates, the minutiae-based matching method is the most widely studied matching method [3]. Today many Smartphone such as iPhone, Infinix, Techno, and many notebook personal computer use fingerprint technology for authentication to $\log$ in to the phone and the computer system.

Student attendance management is the act of managing student's attendance or presence in an academic institution. Student's attendance control system has manually been approached using time clocks and timesheets, but student attendance management goes beyond this to provide a studying environment which maximizes and motivates student's attendance [4]. Every organization, whether it be an educational institution or business organization, has to maintain a proper record of attendance of students or employees for effective functioning of the organization [5]. The process of monitoring attendances in any institution is an important part in determining the efficiency of the services offered by the institution and the general interest of those who benefit from the institution's services, in our case, the students [6]. This system developed will reduce the manual work and avoid redundant data. By maintaining the attendance manually, efficient reports cannot be generated. The system can generate efficient weekly, consolidate report based on the attendance [7]. As the attendances are maintained in registers it has been a tough task for admin and staff to maintain for long time. Instead the software can keep long and retrieve the information when needed [7]. Student 
academic attendance is very important since it will affect the students from gaining knowledge and skills as well as their grades [8]. The main purpose of carrying out this work is to develop a hybrid student attendance system for which desktop-based application is developed to obtain the attendance of student by fingerprint and post/review the attendance results using a the window application [8]. The proposed system has been developed to overcome the drawbacks of the existing system - aiming to reduce the paper work and saving time to generate accurate results from the student's attendance. The system provides user interface. The efficient reports and statistics of student details can be generated by using this proposed system. The most important part of this work is a database containing all the information about students, department and attendance percentage which can serve as criteria for examination pass.

When the first employee time clock was invented in the late 1800 s, its purpose was to record the time an employee entered and left the factory [9]. "This mechanical employee time clock would stamp day and time information on a thick paper card, hence the name 'time card'. This first time card gave the factory owner an actual record of the hours worked by each employee. This protected the business owner by making sure employees worked the number of hours they claimed, and protected employees by making it much more difficult for employers to cheat them out of their wages. Time and attendance systems continued to advance with smaller electrical time clocks eventually replacing the large mechanical ones. Time cards also evolved to have special areas marked on them for clocking in and out, so workers had to carefully line up the time card in just the right place. When commercial time clock software first made its appearance in the 1990s, businesses started moving away from mechanical and electrical time clocks that were subject to failure and expensive to replace or repair. Time clock software allowed business owners to enjoy the benefits of reduced payroll processing costs by making it quick and easy to go directly from time clock to paycheck with increased efficiency while eliminating buddy punching" [9].

One of the existing systems is manual entry of student's name in the attendance sheet. Here the attendance will be carried out in the hand written registers. The human effort is more here as the retrieval of the information is not as easy as the records are maintained in the hand written registers [7]. An embedded computer based lecture attendance management system was proposed. The system provides an improvised electronic card and card reader serially interfaced to the digital computer system [10]. Proposed, also, is an embedded computer-based lecture attendance management system where a single-chip computer based subsystems (an improvised electronic card and the card reader) were interfaced serially to the serial port of the digital computer [11]. "The electronic card is a model of a smart card containing the student identity (ID-Name, Matriculation Number and five pin encrypted code). The student ID is authenticated by the card reader which compares the entrance code with the encrypted code on the card swiped through the card reader. The student is granted and/or denies specific lecture attendance based on the result of the comparison by the backend software system running on the PC to which the card reader is serially interfaced. The system though provided a simplified, low cost embedded computer based system solution to the management of lecture attendance problem in developing countries but does not eliminate the risk of impersonation" [11].

\section{Types of Attendance Management System}

Attendance Management is divided into two categories namely; Conventional and Automated methods. Conventional methods include time sheet, attendance register and time clock [12]. "Time sheets are documents, electronic or otherwise that record what time was spent by the employee on what tasks. Attendance register is an official list of people who are present at an institution or organization. Time clock which is a mechanical (or electronic) time piece used to assist in tracking the hour worked by an employee of a company. Automated methods include Barcode system attendance system, magnetic stripe attendance system, Radio Frequency Identification (RFID) and the biometric attendance system" [12]. The barcode attendance system requires that every employee is issued a badge/card in which there is a barcode [4]. "In order to check into or out of the company, the badge/card is swapped on the time clock, and the data is captured by the clock. In the magnetic stripe attendance system, data is encoded in the magnetic stripe of the employee card. When the card, is swiped through the employee time clock, the information in the card's magnetic stripe is recorded by the time clock. This system reads one card at a time and also requires contact with the reader. Radio-frequency identification (RFID) is a technology that uses radio waves to transfer data from an electronic tag, called RFID tag or label, attached to an object, through a reader for the purpose of identifying and tracking the object. The ID cards of the employees is embedded with RFID tag which is read by a reader. This RFID system is interfaced to a database through a computer. Each employee uses an RFID card and the reader records the data when the employee enters or exits. In biometric Attendance system, there is attendance software that is paired with a time clock for employees which uses biometric technology for authentication purposes. When these systems are in use, the employees can use their biometric data such as finger prints for clocking in and clocking out. This method has the great benefit that the entire process is easy as well as quick. Other advantages include elimination of the cost previously incurred in getting the employees cards" [4].

A fingerprint is the pattern of ridges and valleys on the surface of a fingertip [5]. "The endpoints and crossing points of ridges are called minutiae. It is a widely accepted assumption that the minutiae pattern of each finger is unique and does not change during one's life. Ridge endings are the 
points where the ridge curve terminates, and bifurcations are where a ridge splits from a single path to two paths at a Yjunction" [5]. Figure 1a and $1 \mathrm{~b}$ illustrates an example of a ridge ending and a bifurcation. In this example, the black pixels correspond to the ridges, and the white pixels correspond to the n-valleys.

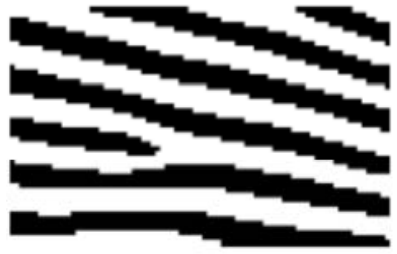

(a) Ridge ending



(b) Bifurcation
Figure 1. Example of a Ridge Ending and a Bifurcation [5].

\section{RFID Technology}

In recent years, there have been rise in the number of applications based on Radio Frequency Identification (RFID) systems and have been successfully applied to different areas as diverse as transportation, health-care, agriculture, and hospitality industry to name a few [13]. "RFID technology facilitates automatic wireless identification using electronic passive and active tags with suitable readers. The application of RFID to student attendance monitoring as developed and deployed in recent years is capable of eliminating time wasted during manual collection of attendance and an opportunity for the educational administrators to capture face-to-face classroom statistics for allocation of appropriate attendance scores and for further managerial decisions" [13]. Figure 2 shows an intersoft RFID reader and the tag.



Figure 2. Intersoft RFID Demo Kit for Student's Attendance [13].

A window application is system software used to program the microchip of the RFID tag, which will contain the details of the student in which the microchip transmit signal through radio waves. When the RFID reader senses the signal being transmitted from the microchip of the RFID tag, it saves the details of the signal being transmitted by the tag to an SD card. The details to be saved are determined by the program content of the microchip. But in this case, the program content of the microchip in the RFID tag (Figure 3) is the details of each student. After every class or after the whole semester, the lecturer will have to connect the SD card to the computer system. Using the same window application, each student details being saved after every class will be reviewed.
The details will be stored in an Excel format (.xlsx) which can also be printed. The computer system in this work serves as a database to the RFID system, because when the window application is launched later even if the SD card is not connected to the system, it will still show the student details being previously saved.
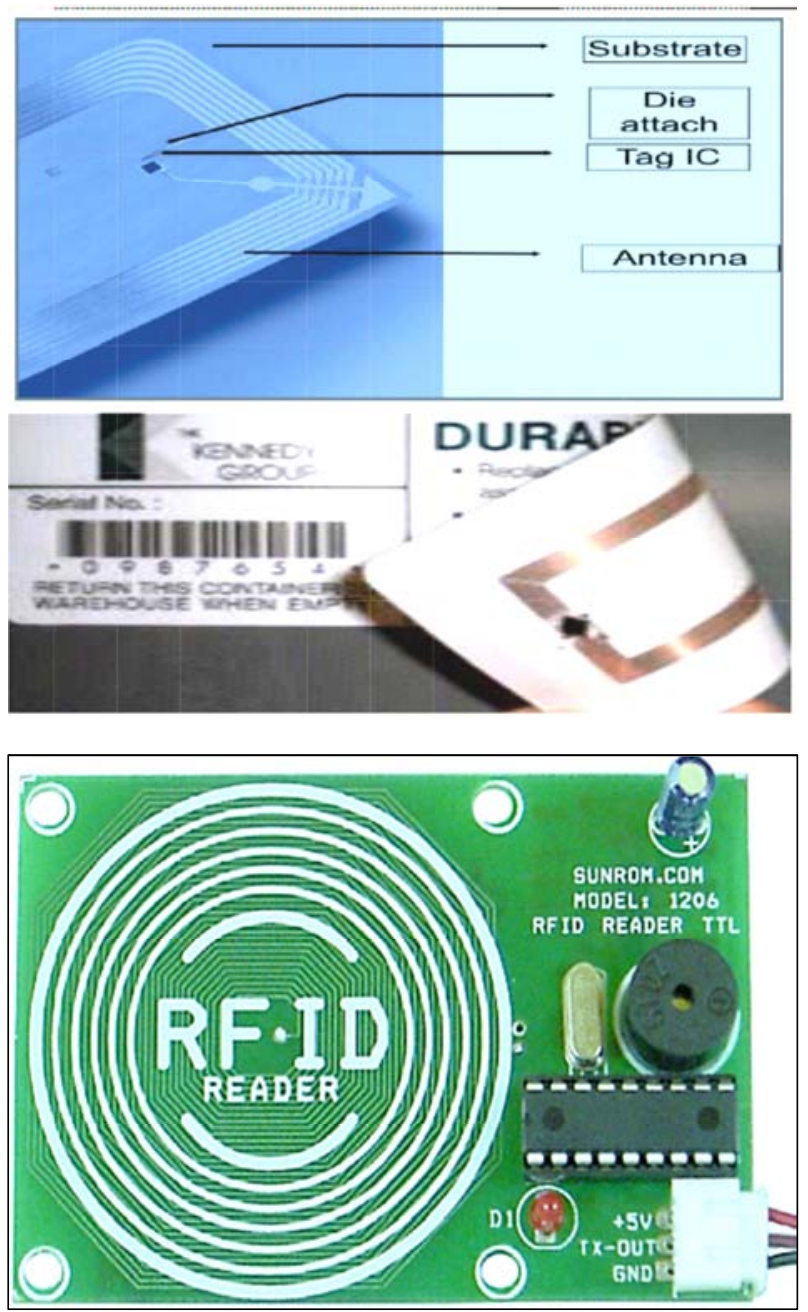

Figure 3. RFID tag and Reader [14]

In the present system, all work is done on paper. The whole session attendance is stored in register and at the end of the session the reports are generated [15]. We are not interested in generating report in the middle of the session or as per the requirement because it takes more time in calculation. At the end of session, the students who don't have $75 \%$ attendance get a notice [15].

\section{Materials and Methods}

The designed functional block diagram is shown below in Figure 4. 


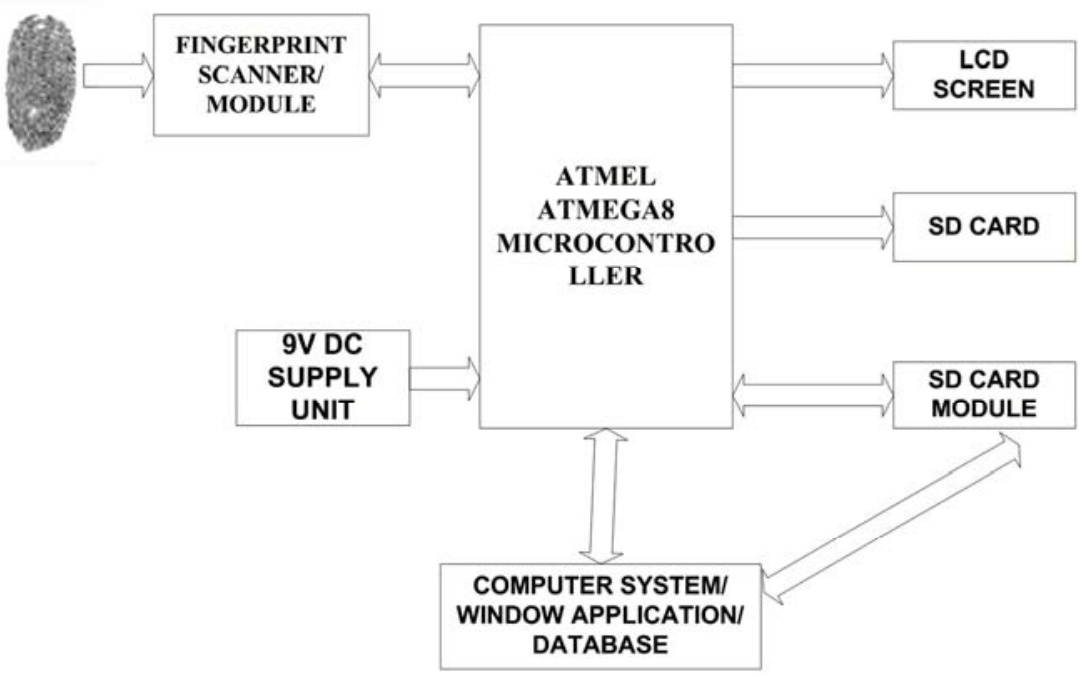

Figure 4. Functional Block Diagram.

\subsection{Fingerprint Module}

Fingerprint acquisition equipment mainly has three kinds: Optical Fingerprint Sensors, Semiconductor Fingerprint Sensors and Ultrasonic Fingerprint Sensors [10]. In this system, R305 fingerprint module is used as shown in Figure 5. It consists of optical fingerprint sensor, high performance DSP processor and Flash. It has $64 \mathrm{~kb}$ user flash memory [10]. "It can store 512 fingerprint templates. It performs the functions such as fingerprint login, fingerprint deletion, fingerprint verification, fingerprint upload, fingerprint download, etc. When reading fingerprint images, it has selfadaptive parameter adjustment mechanism which improves imaging quality for both dry and wet fingers" [10].

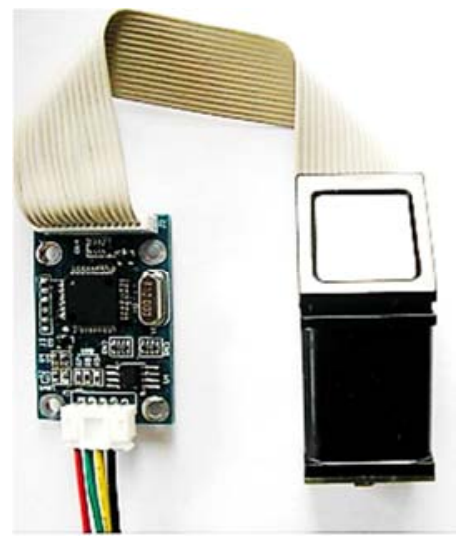

Figure 5. Optical Fingerprint Module R305 [10].

Here, the fingerprint module system has two basic jobs; it gets an image of the finger and it determines whether the pattern of ridges and valleys in this image matches the pattern of ridges and valleys in pre-scanned images.

\subsection{CAMA-AFM32 Semiconductor Fingerprint Sensor Module}

This fingerprint module is for secondary development. It features small size, low power consumption, simple ports, high reliability, small fingerprint template (496 bytes), large fingerprint capacity, etc. It is convenient to be embedded to user system for realizing clients required fingerprint verification products

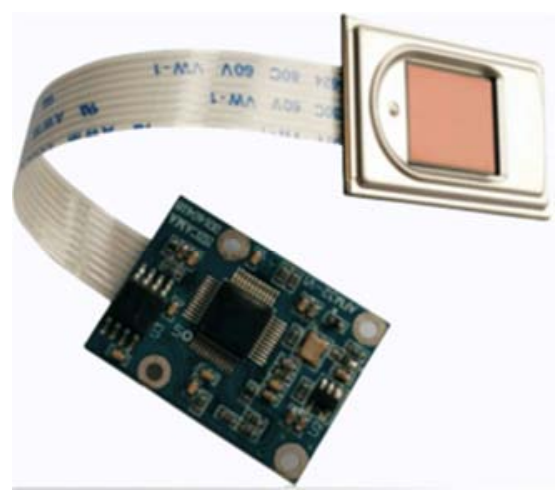

Figure 6. CAMA-AFM32 Semiconductor Fingerprint Sensor Module [10].

\subsection{Ultrasonic Fingerprint Sensors}

This is considerably different to even the best capacitive fingerprint scanners on the market at the moment, which is only able to reproduce $2 \mathrm{D}$ images. $3 \mathrm{D}$ details are much more difficult to forge or fool than 2D versions of the technology, potentially making the ultrasonic system much more secure.

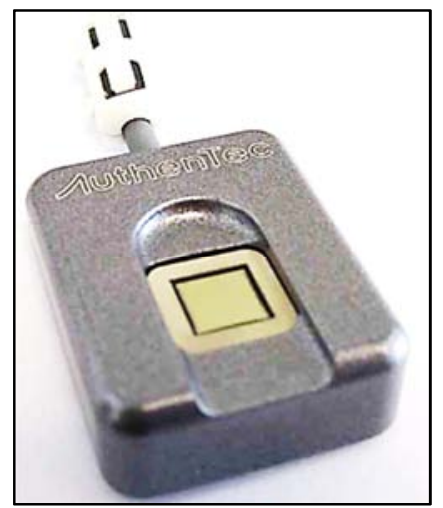

Figure 7. Ultrasonic Fingerprint Sensors [10]. 
Reason for choosing Optical Fingerprint Sensors

a) Availability in market

b) It has high performance DSP processor and Flash

c) It has $64 \mathrm{~kb}$ user flash memory

d) It can store 512 fingerprint templates

\subsection{V DC Supply Unit}

A $9 \mathrm{~V}$ battery or a rectified DC supply can be used to power the microcontroller, the fingerprint module, and the LCD screen. A 9V battery and a rectified 9V DC supply circuit is shown below in Figure 6.

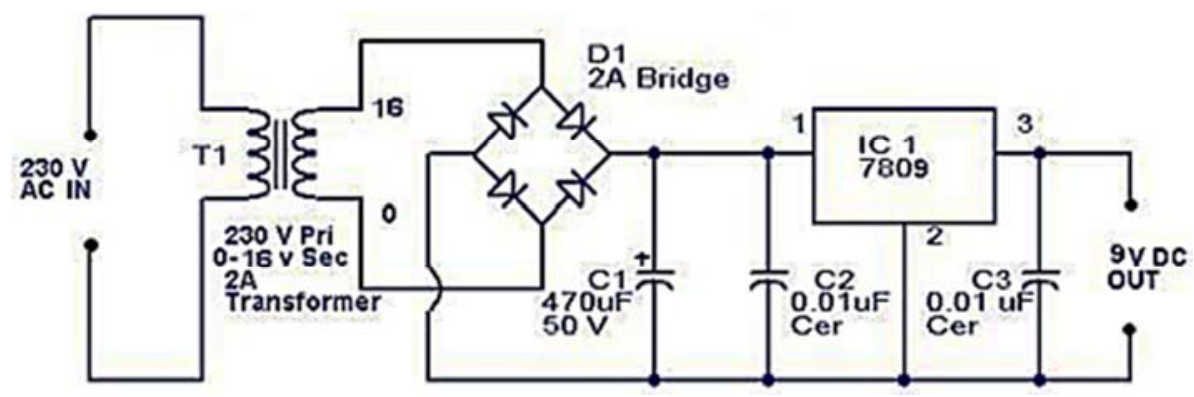

Figure 8. Rectified 9V DC supply.

\subsection{ATMEGA8 Microcontroller}

The Microcontroller is the backbone of the system. In this system, Atmega 8 microcontroller is used. It has $64 \mathrm{kB}$ Flash and 1024 bytes of data RAM [16]. "It is also in Application Programmable (IAP), allowing the Flash program memory to be reconfigured even while the application is running. It drives the control logic behind every functionality, some of which are: Power up and initialize it and dependent modules, Check for interrupts, faults while the modules get initialized, Command the fingerprint module to function as requested by the software interface and enable data transfer through the wireless module" [16].

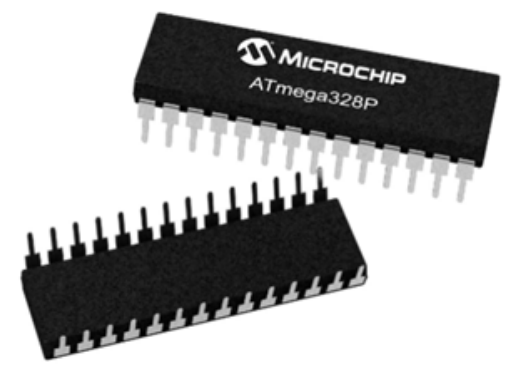

Figure 9. Atmega8 Microchip [17].

\subsection{A $16 X 2$ LCD Screen Module}

LCD (Liquid Crystal Display) screen is an electronic display module with a wide range of applications. A 16x2 LCD display as shown in Figure 8 [18] is a very basic module and is very commonly used in various devices and circuits [19]. The data register stores the data to be displayed on the LCD, Figure 10. The data is the ASCII value of the character to be displayed on the LCD.

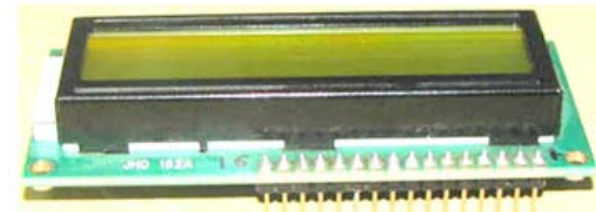

Figure 10. 16 by 2 LCD Screen.

\subsection{An ADRUINO SD Card Module}

The Arduino SD Card module is a simple solution for transferring data to and from a standard SD card. The pin out is directly compatible with Arduino, but can also be used with other microcontrollers. It allows you to add mass storage and data logging to your work [20]. An Arduino SD Card module is shown in Figure 9.

The SD card, Figure 11 and 12, module specifications are as follows; operating voltage of $5 \mathrm{~V}$, SPI Communication method, SD card Socket, Supports FAT16 and FAT32, Support $2 \mathrm{~GB}$ to $4 \mathrm{~GB}$. The SD card saves the attendance details in a, txt file every time the student's attendance is taken. The SD card is connected to the computer system to enable the uploading of the, txt file to the window application.

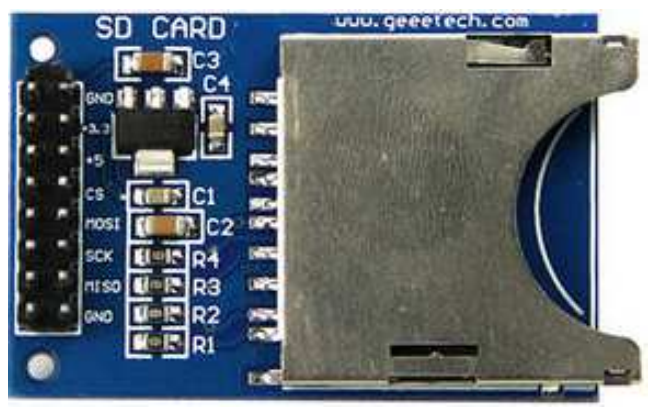

Figure 11. Arduino SD Card Module.

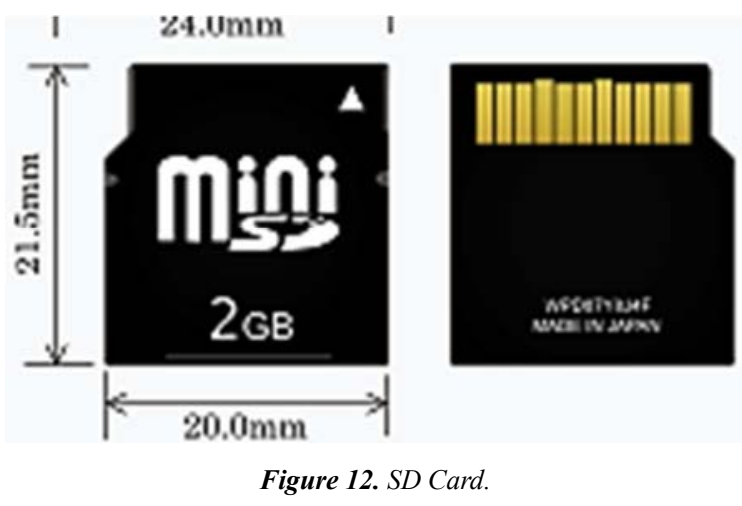




\subsection{Window Application for Database}



Figure 13. System Flow diagram.

The database consists the details of enrolled and registered students which include Id no, Name, Matric number, and department. When the student's fingerprints are enrolled through the window application, it saves the data in the database and then loaded to the microcontroller for recognition when the same fingerprint is being sensed again. The database keeps track of all the student's record and attendance details. The attendance monitoring system software is successfully designed using $\mathrm{C}$ sharp. See appendix A for program source code. The software is designed with an easy to understand user interface, good graphics and the student's details can easily be exported to excel format. The work flow diagram is shown below in Figure 13.

\subsection{Circuit Diagram}

The work circuit diagram is shown below in Figure 14.

In the above circuit layout, every pin with the same label are connected together to other respective modules. The design of this fingerprint-based attendance management system comprises of the following stages: Enrolment stage, Authentication stage, System database.

The task of enrollment module is to enroll student data and their fingerprints into the database. During enrolment, the fingerprint and other bio-data of the student is captured and the unique features are extracted from the fingerprint image and stored in a database as a template for the subject along with the student's ID. Student bio data to be captured includes: ID number, surname, other names, matric number, Department, biometric. To improve the quality of the captured image during enrolment/registration, two image samples per fingerprint are captured for a higher degree of accuracy.

Various screenshots of the software interfaces are explained below. The register and registered students link are explained above in Figure 14 and Figure 15 respectively. Figure 16 below shows the welcome page of the attendance monitoring system software.

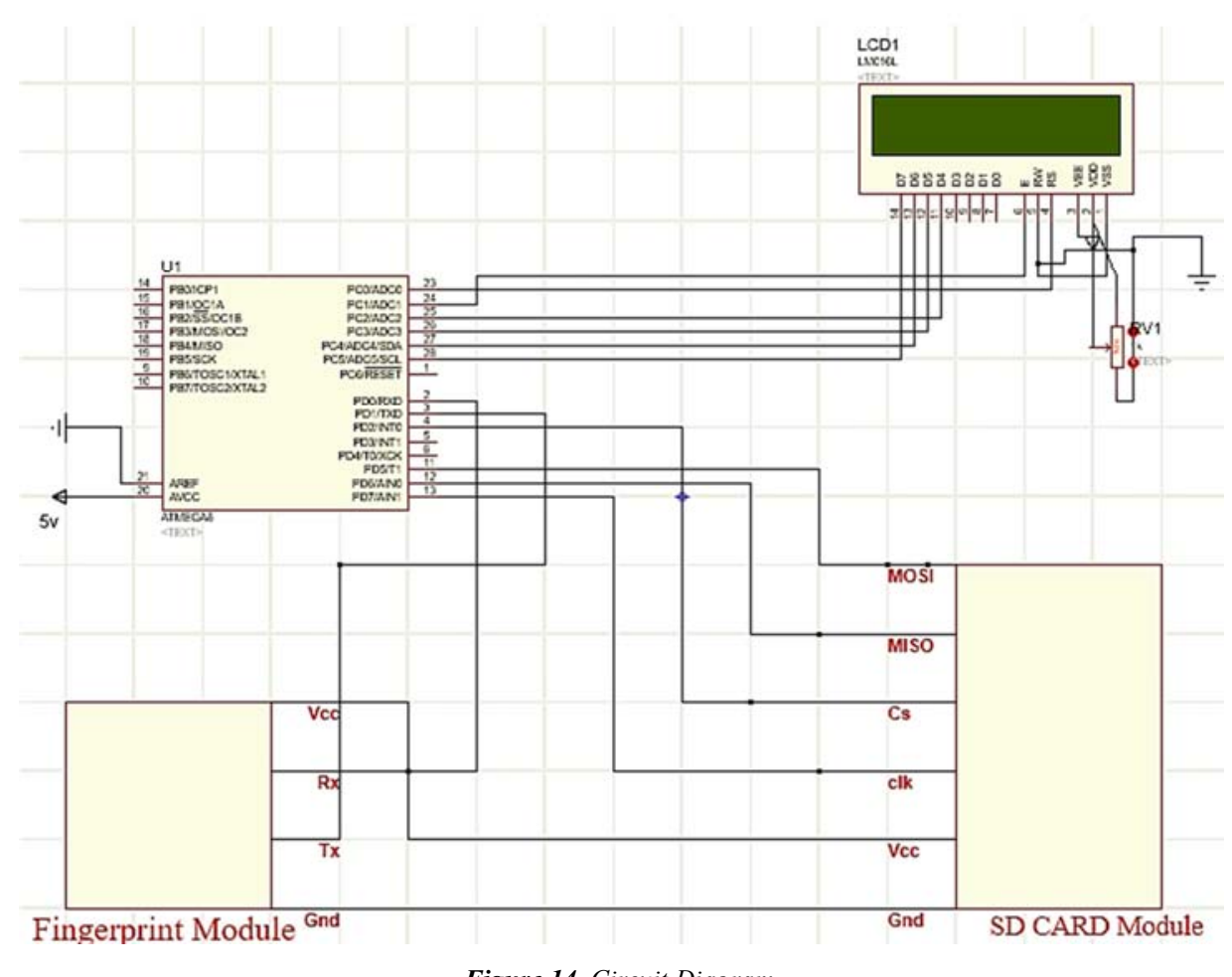

Figure 14. Circuit Diagram. 


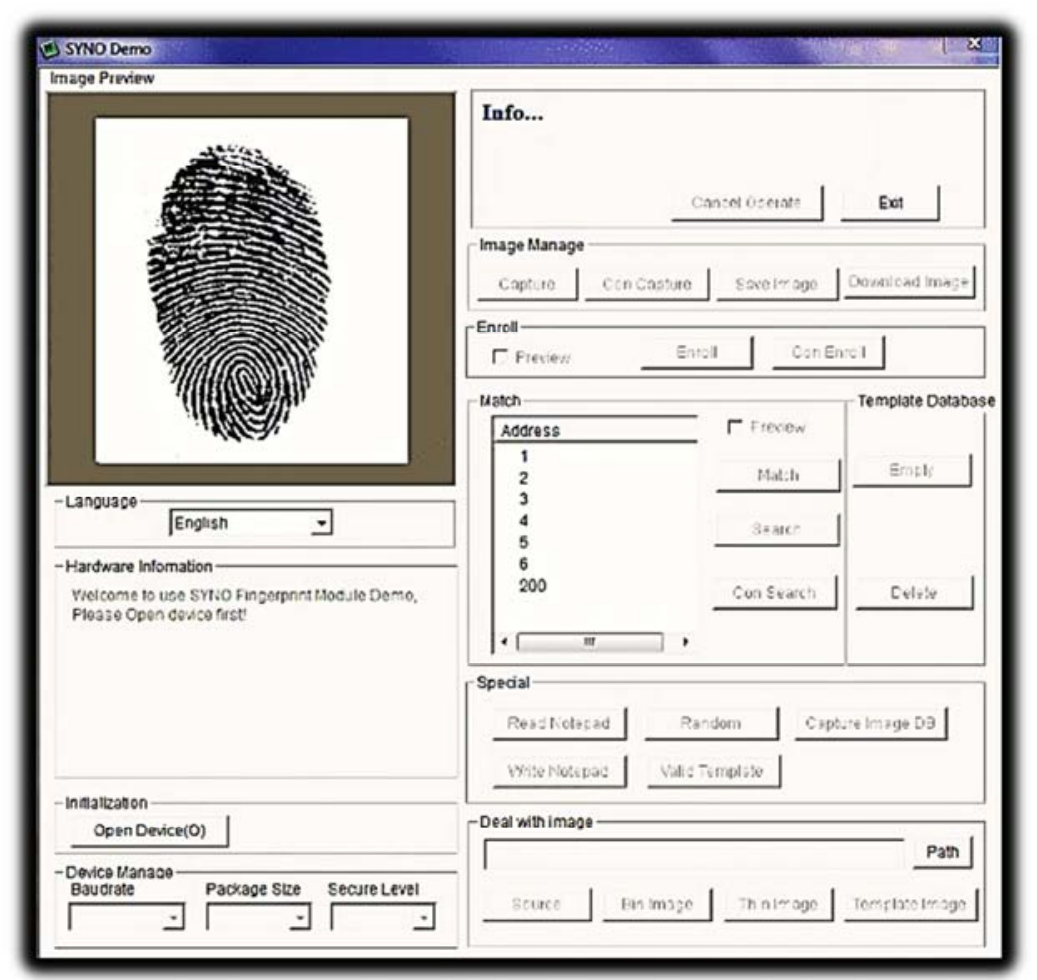

Figure 15. An Interface Showing the Capturing of Student's Fingerprint.

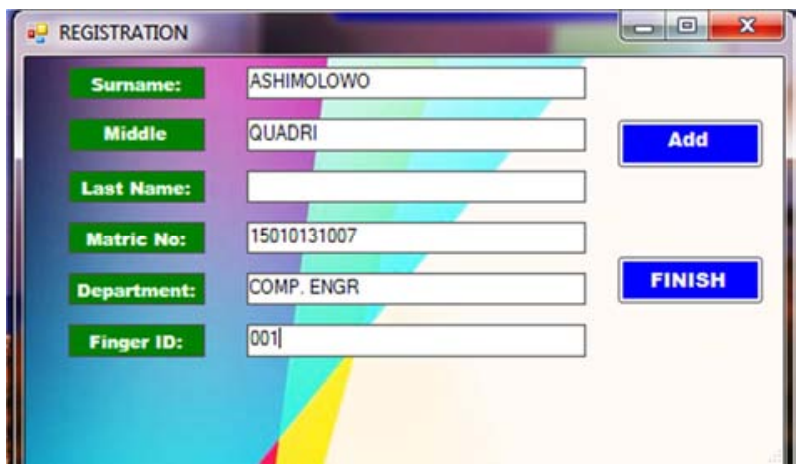

Figure 16. An Interface Showing the Student Registration Page.

When the fingerprint images and the user name of a person to be enrolled are fed to the enrollment module, a minutiae extraction algorithm is first applied to the fingerprint images and the minutiae patterns (features) are extracted [4]. These features form a template that is used to determine the identity of the user, formulating the process of authentication. The enrolment process is carried out by an administrator of the attendance management system. The enrolment and registration phase is an administrative phase. The user fingerprint as well as other bio-data is stored for the first time into the database for registration. All data and information required for the proper recording of attendance are enrolled in this module.

The task of the authentication module is to validate the identity of the person who intends to access the system. The person to be authenticated places his/her finger on the fingerprint scanner. The fingerprint images captured is enhanced and thinned at the image processing stage, and at feature extraction stage, the biometric template is extracted [4]. "It is then fed to a matching algorithm, which matches it against the person's biometric template stored in the system database to establish the identity. During authentication, the student places his/her fingerprint on the fingerprint reader; the fingerprint recognition unit compares the fingerprint features with those stored in the database, after a successful match" [4]. The student's ID number is sent to the database alongside the time of making such attendance and update the status (either present/absent) of student's attendance for the class.

\subsection{The System Database}

The attendance management system database consists of tables that stores records, each of which corresponds to an authorized person that has access to the system. Each record may contain the minutiae templates of the person's fingerprint and user name of the person or other information such as pin no as an index to the template. The database design for the system implements relational data model which is a collections of tables in which data are stored. The database was implemented in Microsoft SQLServer database. SQLServer is fast and easy, it can store a very large record and requires little configuration. Figure 15 shows a database interface that consist the list of registered/enrolled students.

The links in the software main page are explained below ant their respective figures are shown. Figure 17 below shows an interface where student's record can be checked using student's matric number. If the student has been enrolled and registered before in the database, the student's data will be displayed as shown below in Figure 17. 


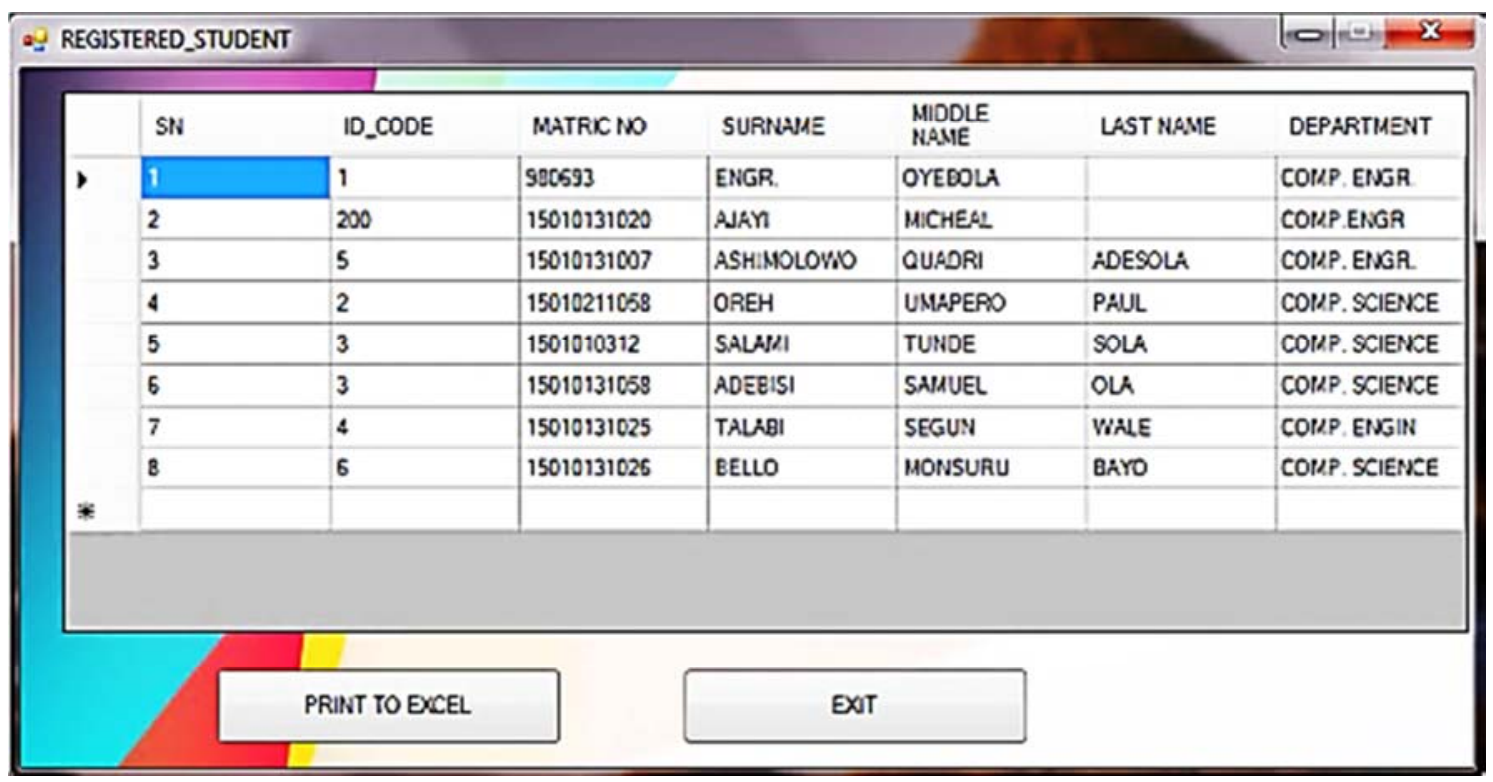

Figure 1. An Interface Showing the List of Enrolled/Registered Students.

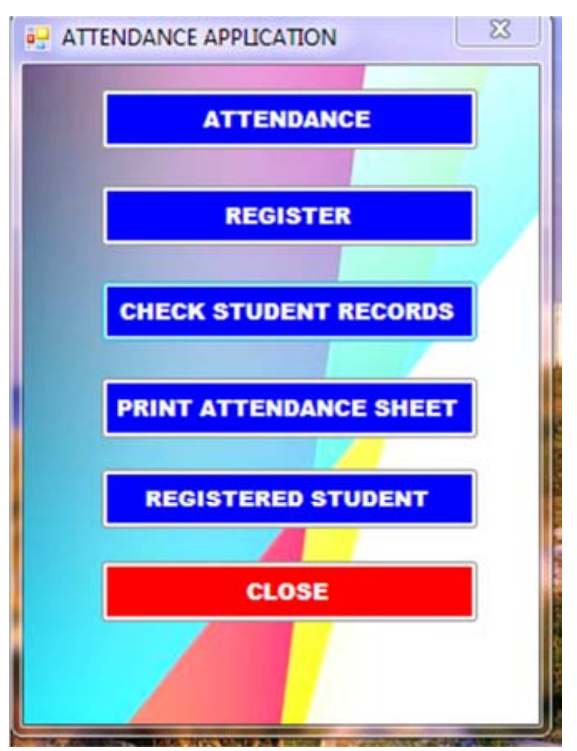

Figure 18. The Designed Attendance Monitoring System Software Welcome Page.

When the student places their finger on the fingerprint module and the attendance is taken, the student ID number is stored in a.txt file in the SD card. After every class, the lecturer or the administrator needs to connect the SD card to the window application in order to access the database and print the attendance list. The.txt file in the SD card will be loaded in the attendance link in accordance with the required date. Figure 18 below shows the attendance link.

In the above diagram, the date of the attendance to be printed is chosen, and the. txt file in the SD card is uploaded using the "Take Attendance Button". After uploading the. txt file, the print attendance link is clicked, in order to print the attendance sheet for the date selected. Figure 19 below shows an interface showing the attendance sheet for a selected date.

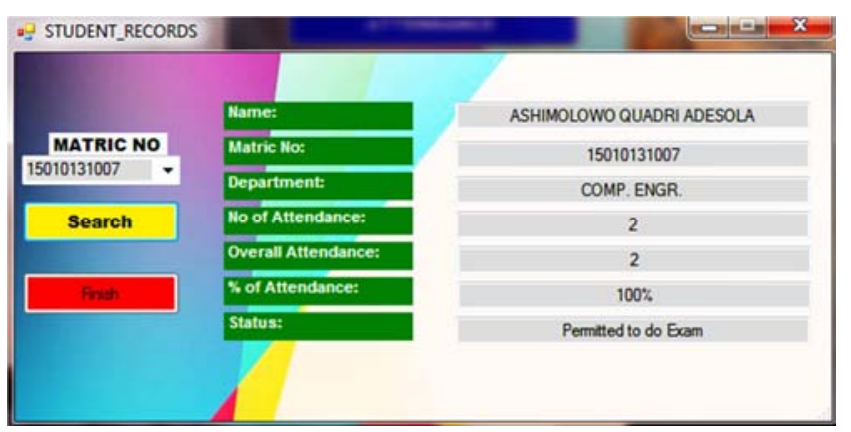

Figure 19. An Interface Showing Students Records Being Searched by Matric Numbers.

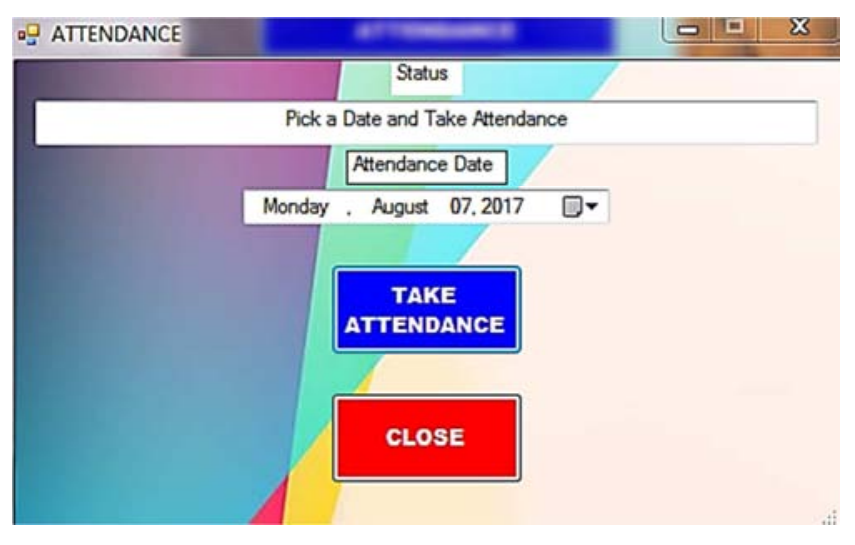

Figure 20. Attendance Link.

\section{Results, Testing and Discussion}

The work is designed in such a way that if any student does not meet the attendance caught off percentage (75\%), the student won't be permitted to sit for the exam. The list of registered students and the attendance list can be exported to an excel format for other documentations. A 9V battery is used to power the device, but in the future, a rectified $9 \mathrm{~V}$ supply can 
be used to power the device as shown above in Figure 6 .

The systm was tested during every stage of the construction and diagrams showing the various stages are shown in Figure 20 and Figure 23.

The device is connected to the window application on the computer system. The device must always be connected to the window application when enrolling and registering students so that the student details can be stored in the database. This was also tested as shown below in Figure 21 efficaciously.

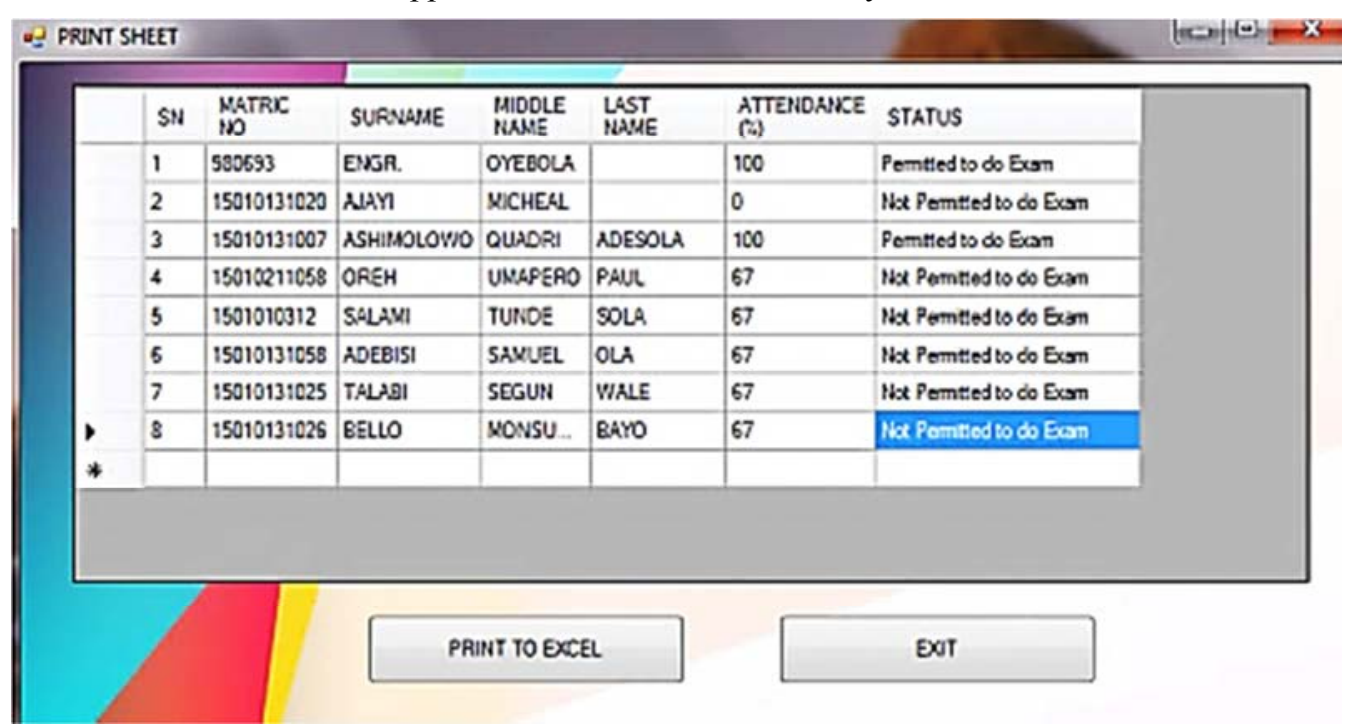

Figure 21. Attendance Sheet.

It was ensured that a rigid and durable packaging and casing was used as shown below in figure 22. The design and construction was successfully completed, tested and well packaged as shown below in Figure 24.

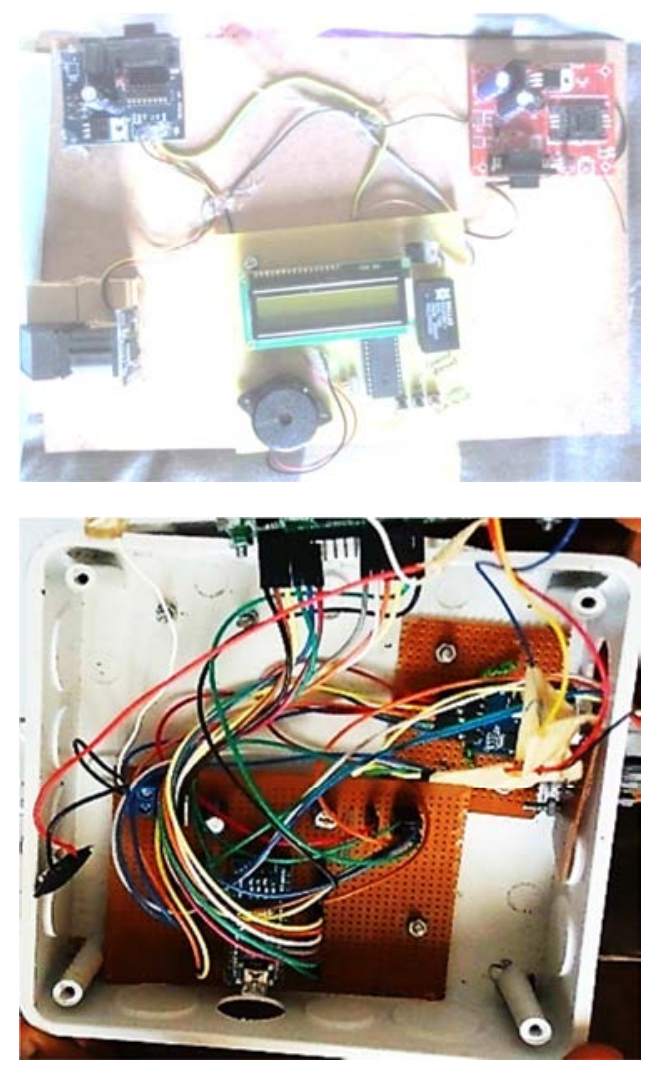

Figure 22. Various Stages during the Construction Process.

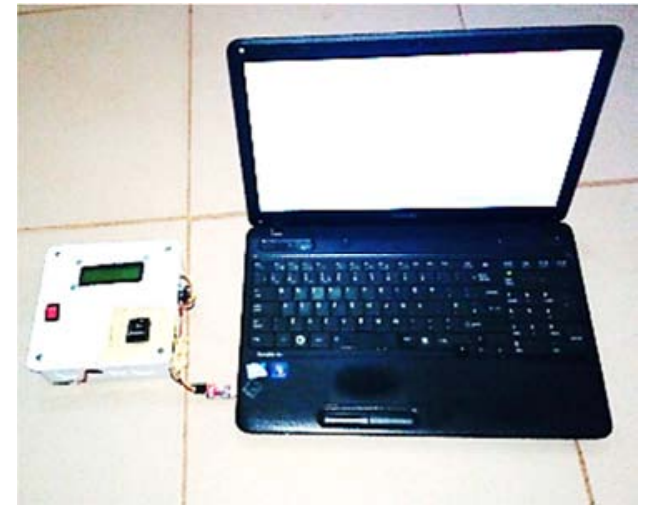

Figure 23. The Device Being Connected to the Window Software.



Figure 24. The Completed Fingerprint Based Student Attendance Management System.

This device can be used in educational institutions. Likewise, biometric attendance system can be used in industries, automated teller machines for additional authentication, for access control and to maintain the criminal attendance or records in prison. The designed 
system has a very high accuracy; it is quite economical biometric authentication technique. It requires small storage space for biometric template, that reduces the size of the database memory required [21]. However, the efficiency of the scanner can be reduced due to the roughages in the captured images which are often caused by worn-out, cut or dirt find on fingerprint. Therefore, there is every possibility that enrolled users can be rejected by the system sometimes. Also the scanner or sensor cannot distinguish between a real and an artificial finger; therefore, it is possible to fool the scanner. In addition, an enrolled fingerprint is very difficult to be duplicated. The system was designed using Visual Basic. net, hence, it would not run on any other platforms other than Microsoft Window operating system.

\section{Conclusions}

The impact of the developed embedded system for student attendance management in tertiary institution, which was the aim of this work, was successfully examined. This provides an effective and more convenient way of taking attendance when compared to the manual system. Data are more organized; the system is user friendly while data manipulation, retrieval and printing are done via the window application.

The system can be implemented in any educational institution. It can be implemented in Gateway (ICT) Polytechnic Saapade, Ogun State, Nigeria. The future student attendance system should be designed and implemented in such a way that a GSM technology will also be embedded in the system so that when student is regularly absent within four days or six days, a free voice call is generated to call the parents mobile number. The system can be further enhanced by integrating multiple face detection and recognition device as a replacement of the fingerprint reader for easy taking of attendance.

\section{References}

[1] Hong, L. (1998). Automatic Personal Identification Using Fingerprint. Michigan: Michigan State University.

[2] Mary, J., \& Aliman, M. (2008). Development of a Fingerprint Classification Scheme for Improved Fingerprint Identification. Diliman: University of the Philippines.

[3] Raymond, T. (2009). Fingerprint Image Enhancement and Minutiae Extraction. Australia: The University of Western Australia.

[4] Akinduyite, C., Adetunmbi, A., Olabode, O., \& Ibidunmoye, E. (2015). Fingerprint Based Attendance Management System. Department of Computer Science. Akure, Ondo State: Federal University of Technology.

[5] Rishabh, M., \& Prashant, T. (2011). Student Attendance System Based On Fingerprint Recognition and One-to-Many Matching. National Institute of Technology Rourkela, Department of Computer Science and Engineering. India: Rourkela-769 008.
[6] Tirmann, V., \& Tăbuşcă, A. (2016). University Student Attendance Management System. Journal Of Information Systems \& Operations Management, $\mathrm{Pp}(1-8)$.

[7] Kalaisankaran, B. (2013). Students Attendance Management System. Dr. Mahalingam College Of Engineering And Technology, Department of Computer Applications, Pollachi.

[8] Liew, K. N. (2015). Fingerprint Recognition Student Attendance Management System. University Tunku Abdul Rahman, Information Systems Engineering. Faculty of Information and Communication Technology.

[9] Redcort. (2011, August 26). Time and Attendance Article: History Of Time And Attendance Systems. Retrieved from Redcort Software:

https://www.redcort.com/blog/2011/08/history-of-time-andattendance-systems.

[10] Sopan, B., Poonam, C., Vaijanti, P., Apurva, S., \& Dhoot, G. (2016, July 06). Fingerprint Based Attendance Management System with SMS Alert to Parents. International Journal of Research in Advent Technology (IJRAT), pp (1-5).

[11] Shoewu, O., Olaniy, M., \& Lawson, A. (2011). Embedded Computer-Based Lecture Attendance Management System. African Journal of Computing and ICT, Vol. 4 (Issue 3), Pp (27-36).

[12] Ononiwu, G., \& Okorafor, N. (2012). Radio Frequency Identification (RFID) Based Attendance System With Automatic Door Unit. International Journal of Academic Research, Vol. 2 (Issue 2).

[13] Arulogun, T., olatunbosun, A., Fakolujo, A., \& Olaniyi, O. (2013). RFID-Based Students Attendance Management System. International Journal of Scientific \& Engineering Research, Volume 4 (Issue 2).

[14] Longe. (2009). Implementation of Student Attendance System using RFID Technology. Ladoke Akintola University of Technology, Ogbomosho.

[15] Amadi, Q. N., Obrki, G., \& Chuwuji, M. (2012). Student Attendance Management System. Work Report, Delta State Polytecnic, Dept. of Comp. Engr, Otefe Oghara.

[16] Mohit, B., Deeksha, R., \& Gunjeet, K. (2016). Biometric Attendance System. International Journal of Engineering Applied Sciences and Technology, Vol. 1 (Issue 6), pp 195-199.

[17] Microchip. (2015). Atmega328P. Retrieved August 11, 2017, from Microchip: http://www.microchip.com/ wwwproducts/en/ATmega328P.

[18] Chamberlin, T. (2012, March 07). 9 V regulator using 7809. Retrieved from Circuits Today: $\mathrm{http}: / /$ www.circuitstoday.com/9-v-regulator-using-7809.

[19] Kenneth, N., \& Josef, B. (2003). Localization of Corresponding Points in Fingerprints by complex Filtering. Pattern Recognition Letter.

[20] Wiki, G. Arduino SD card Module. GTWiki. [Online] July 14, 2014. [Cited: August 11, 2017.] http://www.geeetech.com/wiki/index.php/Arduino_SD_card Module.

[21] Zatin, S., \& Rajneesh, K. G. (2012). Remote Monitoring of Attendance System based on RFID using GSM Network. International Journal of Computer Applications. 